\title{
Depot medroxyprogesterone (Depo-Provera) and risk of breast cancer
}

\author{
Charlotte Paul, D C G Skegg, G F S Spears
}

\begin{abstract}
Objective-To determine whether use of the injectable contraceptive depot medroxyprogesterone acetate (Depo-Provera) affects the risk of breast cancer in women.
\end{abstract}

Design-A population based case-control study.

Setting-Nationwide community study.

Subjects-891 Women aged 25-54 with newly diagnosed breast cancer were compared with 1864 women selected at random from the electoral rolls.

Intervention-Women were interviewed by telephone about past use of contraceptives and about possible risk factors for breast cancer.

Main outcome measure-Relative risk of breast cancer in women who had used medroxyprogesterone.

Results-Medroxyprogesterone had been used by 110 patients and 252 controls. Overall, the relative risk of breast cancer associated with any duration of use was $1.0(95 \%$ confidence interval 0.80 to $1 \cdot 3)$. In women aged $25-34$ the relative risk was $2.0(1.0$ to $3.8)$. The relative risk was highest in women aged 25-34 who had used the drug for six years or longer, although there were few women in this category. Women who had used it for two years or longer before age 25 had an increased risk of breast cancer (relative risk $4.6 ; 1.4$ to $15 \cdot 1$ ).

Conclusion-Despite the lack of an overall association these findings suggest that medroxyprogesterone may increase the risk of breast cancer in young women.

\section{Introduction}

The injectable contraceptive depot medroxyprogesterone acetate (Depo-Provera) has been used by over 10 million women but has still not been approved for marketing in several countries including the United States.' This is partly because it caused malignant mammary tumours in beagles. ${ }^{2}$ The relevance of this finding was debated, ' and there have been few studies of the drug's relevance to breast cancer in women..$^{2-4}$ The drug was introduced in New Zealand in 1969 and has been used more extensively there than in any other developed country.' We conducted a national casecontrol study to find out if there was an association between it and breast cancer.

Subjects were selected from the population of women whose names were in a current electoral roll and whose telephone number could be found.

\section{Subjects and methods}

Details of methods in the first two vears of the study have been described elsewhere." The National Cancer Registry (or, in the Auckland region, the Auckland Breast Cancer Study Group) identified 1452 women aged 25-54 in whom breast cancer had been confirmed histologically between 1 July 1983 and 30 June 1987.
We excluded women who had had breast cancer diagnosed previously, those whose names were not in a current electoral roll, and those whose telephone number could not be found. After these exclusions 1126 patients remained. We required that they be interviewed between four and eight months after diagnosis (this was extended in the third and fourth years to 12 months after diagnosis.) This resulted in the exclusion of some of the women: table I gives the reasons why 225 potentially eligible patients were not interviewed. Forty three patients refused to be interviewed. Interviews were completed with 901 (95\%) of the 944 women approached. After interview 10 were excluded because they had had breast cancer diagnosed previously or because their final diagnosis was not breast cancer.

Control women were selected randomly from the electoral rolls, and women whose telephone numbers could not be found were excluded. As age was not specified in the rolls we had to choose more women than were required. We wrote to these women between 1 November 1983 and 31 October 1987. If they did not reply we telephoned them. Of 4725 women sent letters, 1898 were outside the age range of 25 to 55 . We randomly excluded half of those under age 35 (560 women) so that the age distribution approximated more closely that of the patients. Interviews were completed for 1915 (90\%) of the 2134 women approached. (Table I gives the reasons why 352 potentially eligible controls were not interviewed.) For each a reference date was calculated by subtracting six months from the date of interview to correspond to the mean time between diagnosis and interview in the patients. After their interview 51 women were excluded because they had a history of breast cancer or because they were outside the age range on the reference date.

Women were interviewed by telephone after an initial approach by letter. The letter and interview were designed so that they did not disclose the study's hypotheses. Two nurses conducted $94 \%$ of the interviews and one of us $(\mathrm{CP})$ conducted the rest. Most

TABLE I-Reasons why eligible women with breast cancer or controls were not interviewed

\begin{tabular}{lcc}
\hline & $\begin{array}{c}\text { Patients } \\
\text { eligible for } \\
\text { interview } \\
(\mathrm{n}=1126)\end{array}$ & $\begin{array}{c}\text { Controls } \\
\text { eligible for } \\
\text { interview } \\
(\mathrm{n}-2267)\end{array}$ \\
\hline Died & 17 & 9 \\
Identified too late & 87 & \\
Previously interviewed as a control & 6 & \\
Doctor refused & 51 & 219 \\
Subject refused & 43 & 8 \\
Too ill & 8 & $71 \neq$ \\
Not traced & 4 & 23 \\
Absent overseas & 5 & 22 \\
Language difficulties & 4 & \\
\hline
\end{tabular}

*Ten were excluded after interview.

+Fifty one were excluded after interview.

$\ddagger$ About half of these women would have been outside age range for study. 
began with the interviewer blind to whether the subject was a patient or a control; although patients reported their illness during the interview, this usually occurred after the contraceptive history had been taken. To help the women recall their use of contraceptives our letter was accompanied by a calendar on which they were asked to mark important dates such as marriages and births. We also wrote to the general practitioners of women who had recently used contraceptives that had been prescribed. The contraceptive histories from

TABLE II -Characteristics of women diagnosed as having breast cancer and controls

\begin{tabular}{|c|c|c|c|c|}
\hline Characteristic & $\begin{array}{c}\text { No of } \\
\text { patients } \\
(\mathrm{n}=891)\end{array}$ & $\begin{array}{c}\text { No of } \\
\text { controls } \\
(\mathbf{n}=1864)\end{array}$ & $\begin{array}{l}\text { Relative risk } \\
\text { of breast } \\
\text { cancer }^{\star}\end{array}$ & $\begin{array}{c}95 \% \\
\text { Confidence } \\
\text { interval† }\end{array}$ \\
\hline \multicolumn{5}{|l|}{ Age: } \\
\hline $25-29$ & 15 & 193 & & \\
\hline-34 & 49 & 212 & & \\
\hline-39 & 121 & 404 & & \\
\hline-44 & 203 & 403 & & \\
\hline-49 & 258 & 357 & & \\
\hline-54 & 245 & 295 & & \\
\hline \multicolumn{5}{|l|}{ Ethnic group: } \\
\hline Non-Maori & 829 & 1774 & $1 \cdot 0$ & \\
\hline Naori & 62 & 90 & 1.6 & $1 \cdot 1$ to $2 \cdot 3$ \\
\hline \multicolumn{5}{|l|}{ Age at menarche: } \\
\hline$<12$ & 154 & 289 & $1 \cdot 0$ & \\
\hline-14 & 589 & 1270 & 0.87 & $0 \cdot 69$ to $1 \cdot 1$ \\
\hline$\geqslant 15$ & 146 & 303 & 0.8 & 0.59 to 1.1 \\
\hline Unknown & 2 & 2 & & \\
\hline \multicolumn{5}{|l|}{ Parity: } \\
\hline Nulliparous & 98 & 199 & $1 \cdot 0$ & \\
\hline 1 & 74 & 168 & $0 \cdot 86$ & 0.56 to 1.3 \\
\hline 2 & 260 & 576 & 0.78 & 0.57 to 1.1 \\
\hline 3 & 248 & 479 & 0.72 & 0.52 to 0.99 \\
\hline$\geqslant 4$ & 211 & 442 & 0.51 & 0.36 to 0.72 \\
\hline \multicolumn{5}{|l|}{ Age at first full term pregnancy: } \\
\hline$<20$ & 105 & 260 & $0 \cdot 71$ & 0.49 to 1.0 \\
\hline-24 & 419 & 879 & $0 \cdot 69$ & 0.51 to 0.93 \\
\hline-29 & 198 & 419 & 0.65 & 0.47 to 0.92 \\
\hline$\geqslant 30$ & 71 & 106 & $0 \cdot 78$ & 0.50 to 1.2 \\
\hline Unknown & & 1 & & \\
\hline \multicolumn{5}{|l|}{ Family history of breast cancer: } \\
\hline None & 658 & 1586 & $1 \cdot 0$ & \\
\hline Second degree relative only & 132 & 192 & $1 \cdot 7$ & $1 \cdot 3$ to $2 \cdot 2$ \\
\hline First degree relative & 101 & 86 & $2 \cdot 5$ & 1.8 to 3.5 \\
\hline \multicolumn{5}{|c|}{ History of surgery for benign breast disease: } \\
\hline No & 774 & 1730 & $1 \cdot 0$ & \\
\hline Yes & 117 & 134 & $1 \cdot 7$ & $1 \cdot 3$ to $2 \cdot 2$ \\
\hline
\end{tabular}

TABLE III - Relative risk ${ }^{\star}$ of breast cancer (and 95\% confidence interval) according to how long women had used medroxyprogesterone and age at diagnosis of those with breast cancer and comparable age of controls

\begin{tabular}{|c|c|c|c|c|}
\hline \multirow[b]{2}{*}{ Duration of use } & \multicolumn{4}{|c|}{ Age at diagnosis } \\
\hline & $25-34$ & $35-44$ & $45-54$ & All ages \\
\hline Never & $\begin{array}{l}1 \cdot 0 \\
(48,350)\end{array}$ & $\begin{array}{l}1 \cdot 0 \\
.(276,674)\end{array}$ & $\begin{array}{l}1 \cdot 0 \\
(457,588)\end{array}$ & $\stackrel{1 \cdot 0}{(781,1612)}$ \\
\hline$<2$ years & $\begin{array}{c}2 \cdot 1(1 \cdot 0 \text { to } 4 \cdot 4) \\
(13,38)\end{array}$ & $\begin{array}{c}0.97(0.63 \text { to } 1 \cdot 5) \\
(34,92)\end{array}$ & $\begin{array}{c}1 \cdot 1(0 \cdot 66 \text { to } 1.9) \\
(28,34)\end{array}$ & $\begin{array}{c}1 \cdot 1(0 \cdot 84 \text { to } 1 \cdot 5) \\
(75,164)\end{array}$ \\
\hline $2-5$ years & $\begin{array}{c}0.75(0 \cdot 1 \text { to } 6 \cdot 1) \\
(1,12)\end{array}$ & $\begin{array}{c}0 \cdot 75(0 \cdot 33 \text { to } 1 \cdot 7) \\
(8,28)\end{array}$ & $\begin{array}{c}0 \cdot 73(0.35 \text { to } 1 \cdot 5) \\
(11,20)\end{array}$ & $\begin{array}{c}0 \cdot 72(0 \cdot 42 \text { to } 1 \cdot 2) \\
\quad(20,60)\end{array}$ \\
\hline$\geqslant 6$ years & $\begin{array}{l}3 \cdot 7(0.63 \text { to } 21 \cdot 5) \\
\quad(2,5)\end{array}$ & $\begin{array}{l}1 \cdot 2(0 \cdot 45 \text { to } 3 \cdot 3) \\
\quad(6,13)\end{array}$ & $\begin{array}{l}0 \cdot 86(0 \cdot 32 \text { to } 2 \cdot 3) \\
\quad(7,10)\end{array}$ & $\begin{array}{l}1 \cdot 2(0 \cdot 59 \text { to } 2 \cdot 2) \\
(15,28)\end{array}$ \\
\hline All users & $\begin{array}{c}2 \cdot 0(1 \cdot 0 \text { to } 3 \cdot 8) \\
(16,55)\end{array}$ & $\begin{array}{l}0.94(0.65 \text { to } 1.4) \\
\quad(48,133)\end{array}$ & $\begin{array}{c}0.95(0.63 \text { to } 1.4) \\
(46,64)\end{array}$ & $\begin{array}{c}1 \cdot 0(0 \cdot 80 \text { to } 1 \cdot 3) \\
\quad(110,252)\end{array}$ \\
\hline
\end{tabular}

*Compared with women in each age group who had never used medroxyprogesterone. Relative risks are adjusted for age (within each 10 year age group), parity, ethnic group, and year of interview.

+Numbers of patients and controls shown in parentheses.

TABLE IV-Relative risk ${ }^{\star}$ of breast cancer (and $95 \%$ confidence interval) according to how long patients with breast cancer and controls had used medroxyprogesterone and age at which they had first used it $千$

\begin{tabular}{|c|c|c|c|c|}
\hline \multirow[b]{2}{*}{ Duration of use } & \multicolumn{4}{|c|}{ Age at first use } \\
\hline & $<25$ & $25-29$ & $\geqslant 30$ & All ages \\
\hline$<2$ years & $\begin{array}{c}1.5(0.77 \text { to } 2 \cdot 8) \\
(14,44)\end{array}$ & $\begin{array}{c}0 \cdot 78(0.44 \text { to } 1 \cdot 4) \\
(17,60)\end{array}$ & $\begin{array}{c}1 \cdot 3(0 \cdot 84 \text { to } 1 \cdot 9) \\
\quad(44,60)\end{array}$ & $\begin{array}{l}1 \cdot 1(0 \cdot 84 \text { to } 1 \cdot 5) \\
\quad(75,164)\end{array}$ \\
\hline $2-5$ years & $\begin{array}{c}0.62(0.13 \text { to } 2 \cdot 9) \\
(2,15)\end{array}$ & $\begin{array}{c}0.85(0 \cdot 33 \text { to } 2 \cdot 2) \\
\quad(6,19)\end{array}$ & $\begin{array}{l}0.68(0.34 \text { to } 1.4) \\
(12,26)\end{array}$ & $\begin{array}{c}0 \cdot 72(0.42 \text { to } 1 \cdot 2) \\
(20,60)\end{array}$ \\
\hline$\geqslant 6$ years & $\begin{array}{l}4 \cdot 2(1 \cdot 1 \text { to } 16 \cdot 2) \\
(4,6)\end{array}$ & $\begin{array}{l}0.77(0.20 \text { to } 2.9) \\
\quad(3,9)\end{array}$ & $\begin{array}{l}0 \cdot 87(0 \cdot 35 \text { to } 2 \cdot 1) \\
(8,13)\end{array}$ & $\begin{array}{l}1 \cdot 2(0 \cdot 59 \text { to } 2 \cdot 2) \\
\quad(15,28)\end{array}$ \\
\hline All users & $\begin{array}{l}1 \cdot 5(0 \cdot 85 \text { to } 2 \cdot 6) \\
\quad(20,65)\end{array}$ & $\begin{array}{l}0.79(0.50 \text { to } 1.3) \\
\quad(26,88)\end{array}$ & $\begin{array}{c}1 \cdot 1(0 \cdot 75 \text { to } 1 \cdot 5) \\
(64,99)\end{array}$ & $\begin{array}{l}1 \cdot 0(0 \cdot 80 \text { to } 1 \cdot 3) \\
\quad(110,252)\end{array}$ \\
\hline
\end{tabular}

*Compared with women who had never used medroxyprogesterone. Relative risks are adjusted for age, parity, * Compared with women who had

tNumbers of patients and controls shown in parentheses. the general practitioners agreed closely with those obtained from the women. Thus reports as to whether they had used depot medroxyprogesterone in the past five years agreed in all of 74 patients and in 249 out of 253 controls.

Use of contraceptives before diagnosis of breast cancer in the patients and before the reference date in the controls was considered in the analyses. We used standard statistical methods for analysing case-control studies. ${ }^{6}$ We adjusted for age in groups of five years (except for the analysis in table III in which age was adjusted for as a continuous variable within each age group of 10 years). For tests of trend the actual duration of exposure was used.

\section{Results}

Table II summarises the characteristics of the patients and controls. The mean age was higher in the patients ( 45 years) than the controls $(41)$. For all other variables the table gives estimates of relative risks adjusted for age. Other potentially confounding variables examined included menopausal state, history of breast feeding, body mass index, area of residence, social class, education, use of oral contraceptives (total use and use before the first full term pregnancy), cigarette smoking, and alcohol consumption.

The proportions of patients and controls who had used medroxyprogesterone were $12 \cdot 3 \%(110 / 891)$ and $13.5 \%(252 / 1864)$, respectively. Overall, the relative risk for those who had used it (adjusted for potentially confounding variables by logistic regression) was 1.0 (95\% confidence interval $0 \cdot 80$ to $1 \cdot 3$ ). Table III gives the relative risk of breast cancer according to age at diagnosis or reference date and duration of use of medroxyprogesterone; risks were calculated relative to women in the same age group who had never used the drug. Overall, there was no increase in risk with duration of use. In women aged 25-34, however, the relative risk for those who had used it was $2 \cdot 0(1 \cdot 0$ to $3 \cdot 8)$ and the highest risk was in women who had received it for six years or longer (relative risk $3 \cdot 7 ; 0.63$ to $21 \cdot 5)$. The trend in risk with duration of use was significant in this age group $(p<0.001)$, although the significance depended on the difference between those who had used the drug and those who had not.

Table IV gives the relative risks of breast cancer according to the age at which the women first used medroxyprogesterone. In women who had first used it before age 25 the relative risk was $1.5(0.85$ to $2 \cdot 6)$. Again the highest risk was in women in this group who had used it for six years or longer: their risk was raised significantly (relative risk $4 \cdot 2 ; 1 \cdot 1$ to $16 \cdot 2$ ). The trend in risk with duration of use was marginally significant in this group $(p=0.06)$. In women who had first used the drug when they were older than 25 there was no increased risk of breast cancer. In an attempt to disentangle the effects of age at first use of medroxyprogesterone and age at diagnosis we estimated relative risks stratified according to both of these variables. The distributions of patients and controls did not identify either of these variables as the key factor.

Table $\mathrm{V}$ gives the risks associated with duration of use of medroxyprogesterone before age 25 and before the first full term pregnancy relative to women who had not used it before these times. Use for two years or longer before age 25 was associated with a significantly increased risk of breast cancer (relative risk $4.6 ; 1 \cdot 4$ to $15 \cdot 1)$. The trend in risk with duration of use was significant $(p=0 \cdot 03)$. Only four patients and 22 controls had used the drug before their first pregnancy. The results suggested the possibility of an increased risk in women who had used the drug long term before the first pregnancy, but the numbers were too small to draw conclusions. 
TABLE $\mathrm{V}-$ Relative risk ${ }^{\star}$ of breast cancer (and 95\% confidence interval) according to how long patients with breast cancer and controls had used medroxyprogesterone before age 25 and before their first full term pregnancy†

\begin{tabular}{lcc}
\hline Duration of use & Use before age 25 & $\begin{array}{c}\text { Use before } \\
\text { first pregnancy }\end{array}$ \\
\hline Non-users & $1 \cdot 0$ & $1 \cdot 0$ \\
$<2$ years & $\begin{array}{l}(871,1799) \\
(0 \cdot 65 \text { to } 2 \cdot 2)\end{array}$ & $\begin{array}{c}(887,1842) \\
(2,19)\end{array}$ \\
$2-5$ years & $\begin{array}{c}(15,54) \\
(1 \cdot 4 \text { to } 15 \cdot 1)\end{array}$ & $\begin{array}{c}3 \cdot 2(0 \cdot 41 \text { to } 24 \cdot 3) \\
(2,3)\end{array}$ \\
\hline All users & $(5,11)$ & $\begin{array}{c}1.58(0 \cdot 19 \text { to } 1 \cdot 8) \\
(4,22)\end{array}$ \\
\hline
\end{tabular}

^Compared with women who had not used medroxyprogesterone before age 25 or their first pregnancy. Relative risks are adjusted for age, parity, ethnic group, and year of interview.

†Numbers of patients and controls shown in parentheses.

Table VI gives the relative risks of breast cancer according to time since the women first and last used the drug. Both analyses show a similar pattern, with an apparent increase in risk in women who had used it recently and an apparent reduction in those who had used it many years earlier. For time since first use none of the estimates of relative risk for all users differed significantly from 1 and the trend in risk according to actual time since first use was not significant. Women who had last used the drug within five years were at increased risk (relative risk $1.6 ; 1.0$ to 2.5 ). In such women the highest estimate of relative risk $(2 \cdot 2)$ was in the category of shortest duration of use. Within each category the relative risk declined with increasing time since last use, although the overall trend in risk according to actual time since last use (after exclusion of women who had never used the drug) was not significant.

\section{Discussion}

Our results show that there was no overall association between use of medroxyprogesterone and risk of breast cancer. Increased relative risks were seen, however, in women who had used the drug and were diagnosed as having breast cancer before age 35 ; in those who used it for at least two years before age 25; and in those who had used it recently. The numbers of women who had used the drug for long periods were small, but the highest relative risks in young women and in women who had used it before age 25 were in those who had used it long term. The estimates of relative risk were adjusted for potential confounding factors; adjustment for use of oral contraceptives did not affect the results.

Although chance seems an unlikely explanation for these findings, possible sources of bias must be considered. Selection bias should have been minimised by selecting patients and controls from the population of New Zealand by the same criteria. Information bias was also unlikely to have affected the results: patients and controls were interviewed in an identical way, with the interviewer usually blind to whether the woman was a patient or a control, and contraceptive histories obtained from general practitioners agreed closely with those obtained from the women.

If women using medroxyprogesterone were more likely to examine their breasts frequently or to have them examined by a doctor or nurse surveillance bias could arise. This was considered as a possible explanation for the increased risk of breast cancer in women who had used the drug recently (table VI). During the second half of the study we asked women how often they had examined their breasts or had had them examined more than one year before the interview. The proportions of controls who had had one or more breast examinations yearly were identical $(72 \%)$ in women who had and had not used the drug, although there was a small difference for women under 35 . Furthermore, of the 110 women with breast cancer who had used the drug, only eight were using it around the time of diagnosis. Surveillance bias is not a likely explanation for the positive findings.

Another explanation for the results in table VI could be that medroxyprogesterone increases the risk of breast cancer but only during the first few years after exposure. This would imply that it acts as a promoter during the late stages of carcinogenesis. Such an effect might be comparable to the initial influence of pregnancy. A full term pregnancy may be followed by a short term increase in risk of breast cancer, which, after some years, is superseded by the protective effect of parity. ${ }^{89}$ The data in table VI suggest that medroxyprogesterone may also have an initial harmful effect followed by a protective effect. The fact that this dual pattern was found in women older than 35 might explain the lack of any overall alteration of risk in this age group.

Medroxyprogesterone is a potent progestogen, which is delivered to the body in relatively high concentrations: ${ }^{10}$ Endogenous progesterone was formerly thought to exert a protective effect by opposing oestrogen in the induction of breast cancer. ${ }^{11}$ This hypothesis is not consistent with epidemiological evidence, ${ }^{12}$ and Pike and Ross suggested that raised progesterone concentrations may increase the risk of breast cancer. ${ }^{13}$ Medroxyprogesterone at low and high doses causes mammary carcinomas in beagles, ${ }^{12}$ but the relevance of this finding has been disputed. ${ }^{14^{15}} \mathrm{~A}$ public board of inquiry in the United States, however, reviewed the arguments for dismissing the beagle model and concluded that none had been substantiated adequately. ${ }^{2}$

Epidemiological data on the association between medroxyprogesterone and breast cancer in women are sparse and conflicting. Early studies, including two from Atlanta, ${ }^{16}{ }^{17}$ were difficult to interpret because of methodological limitations. ${ }^{23}$ In a recent case-control study in Costa Rica, women using the drug had a significantly increased relative risk of breast cancer of $2 \cdot 6$. $^{+}$This estimate was based on only 19 cases who had used the drug, and the authors suggested that the

TABLE VI-Relative risk ${ }^{\star}$ of breast cancer (and 95\% confidence interval) according to time since first and last use of medroxyprogesterone (years) in patients with breast cancer and controlst

\begin{tabular}{|c|c|c|c|c|c|c|c|c|}
\hline \multirow[b]{2}{*}{ Duration of use } & \multicolumn{4}{|c|}{ Time since first use } & \multicolumn{3}{|c|}{. : Time since last use } & \multirow[b]{2}{*}{ All times } \\
\hline & $<5$ & $5-9$ & $10-14$ & $\geqslant 15$ & $<5$ & $5-9$ & $\geqslant 10$ & \\
\hline$<2$ years & $\begin{array}{c}2 \cdot 3(1 \cdot 1 \text { to } 4 \cdot 9) \\
(13,16)\end{array}$ & $\begin{array}{c}1 \cdot 2(0 \cdot 70 \text { to } 2 \cdot 1) \\
(21,55)\end{array}$ & $\begin{array}{l}0.90(0.58 \text { to } 1.4) \\
\quad(30,75)\end{array}$ & $\begin{array}{c}1 \cdot 1(0 \cdot 51 \text { to } 2 \cdot 4) \\
(11,18)\end{array}$ & $\begin{array}{c}2 \cdot 2(1 \cdot 1 \text { to } 4 \cdot 5) \\
(15,22)\end{array}$ & $\begin{array}{c}1 \cdot 1(0.68 \text { to } 1.9) \\
(23,61)\end{array}$ & $\begin{array}{c}0.93(0.61 \text { to } 1.4) \\
(37,81)\end{array}$ & $\begin{array}{c}1 \cdot 1(0 \cdot 84 \text { to } 1 \cdot 5) \\
(75,164)\end{array}$ \\
\hline $2-5$ years & $\begin{array}{c}0 \cdot 79(0 \cdot 20 \text { to } 3 \cdot 2) \\
(3,8)\end{array}$ & $\begin{array}{c}1 \cdot 3(0 \cdot 54 \text { to } 3 \cdot 1) \\
(9,17)\end{array}$ & $\begin{array}{c}0 \cdot 58(0 \cdot 23 \text { to } 1 \cdot 5) \\
(6,23)\end{array}$ & $\begin{array}{c}0 \cdot 30(0 \cdot 07 \text { to } 1 \cdot 4) \\
(2,12)\end{array}$ & $\begin{array}{c}1 \cdot 4(0 \cdot 61 \text { to } 3 \cdot 0) \\
(11,19)\end{array}$ & $\begin{array}{c}0 \cdot 69(0 \cdot 29 \text { to } 1 \cdot 6) \\
(7,25)\end{array}$ & $\begin{array}{c}0.21(0.05 \text { to } 0.92) \\
(2,16)\end{array}$ & $\begin{array}{c}0 \cdot 72(0 \cdot 42 \text { to } 1 \cdot 2) \\
(20,60)\end{array}$ \\
\hline$\geqslant 6$ years & - & $\begin{array}{l}0 \cdot 94(0 \cdot 24 \text { to } 3 \cdot 7) \\
(3,10)\end{array}$ & $\begin{array}{c}1 \cdot 6(0 \cdot 69 \text { to } 3 \cdot 8) \\
(10,13)\end{array}$ & $\begin{array}{l}0 \cdot 50(0 \cdot 10 \text { to } 2 \cdot 6) \\
\quad(2,5)\end{array}$ & $\begin{array}{c}1 \cdot 3(0 \cdot 60 \text { to } 2 \cdot 8) \\
\quad(11,21)\end{array}$ & $\begin{array}{l}1 \cdot 0(0 \cdot 28 \text { to } 3 \cdot 8) \\
(4,6)\end{array}$ & $\begin{array}{l}0 \cdot 0 \\
(0,1)\end{array}$ & $\begin{array}{c}1 \cdot 2(0 \cdot 59 \text { to } 2 \cdot 2) \\
(15,28)\end{array}$ \\
\hline All users & $\begin{array}{l}1 \cdot 7(0 \cdot 88 \text { to } 3 \cdot 4) \\
\quad(16,24)\end{array}$ & $\begin{array}{c}1 \cdot 2(0 \cdot 76 \text { to } 1 \cdot 9) \\
(33,82)\end{array}$ & $\begin{array}{l}0.92(0.64 \text { to } 1 \cdot 3) \\
\quad(46,111)\end{array}$ & $\begin{array}{l}0 \cdot 73(0.39 \text { to } 1 \cdot 4) \\
\quad(15,35)\end{array}$ & $\begin{array}{c}1 \cdot 6(1 \cdot 0 \text { to } 2 \cdot 5) \\
\quad(37,62)\end{array}$ & $\begin{array}{l}0.99(0.65 \text { to } 1.5) \\
(34,92)\end{array}$ & $\begin{array}{l}0.78(0.53 \text { to } 1 \cdot 2) \\
\quad(39,98)\end{array}$ & $\begin{array}{c}1 \cdot 0(0 \cdot 80 \text { to } 1 \cdot 3) \\
(110,252)\end{array}$ \\
\hline
\end{tabular}

${ }^{\star}$ Compared with women who had never used medroxyprogesterone. Relative risks are adjusted for age, parity, ethnic group, and year of interview

†Numbers of patients and controls shown in parentheses. 
findings could have been due to bias. The World Health Organisation is studying the risk of cancer in women using medroxyprogesterone at centres in Thailand, Kenya, and Mexico. ${ }^{3}$ The most recent report from this case-control study (based on 39 cases who had used medroxyprogesterone) yielded a relative risk for all women using the drug of 1.0 ( $95 \%$ confidence interval 0.7 to $1 \cdot 5){ }^{3}$ Relative risks were not shown separately for women diagnosed as having breast cancer before age 35, for women who used the drug before age 25 , or for women who reported using it recently; it will be important to see whether more detailed analyses replicate our findings and, if so, which of these groups are specifically at risk.

If our results are confirmed the indications for using medroxyprogesterone will need to be reassessed. The findings will also contribute to discussions about the relevance of the beagle model and about the pathogenesis of breast cancer.

This research was supported by grants from the Medical Research Council of New Zealand and from the World Health Organisation's special programme of research, development, and research training in human reproduction. We thank Mrs Celia Harris and Mrs Janet Thomson (the interviewers); Mrs Judith Smeijers, Mrs Isabel Pairman, and Mr Peter Herbison $\mathrm{Mr}$ Jim Fraser and Miss Jackie Auld of the National Cancer Registry; Professor Ronald Kay, Miss Barbara Mason, and Mrs Lorraine Neave of the Auckland Breast Cancer Study Group; and the women who participated in the study and the surgeons and general practitioners who supported it.
1 World Health Organisation. Facts about injectable contraceptives: memo randum from a W'HO meeting. Bull W'HO 1982:60:199-210.

2 Weisz J, Ross (iT, Stolley PD. Report of the public hourd of inquiry on Depe Prowera. Reckville, Maryland: L'nited States Food and Drug Administra tion, 1984

3 World Health (Organisation. Depot-medruxyprogesterone acetate (1)MPA and cancer: memorandum from a WHO meeting. Bull WHO 1986;64: $375-82$.

4 Lee NC, Rosero-Bixby L, Oberle MW, Grimaldo C, Whatley AS, Rovira EZ A case-control study of breast cancer and hormonal contraception in Costa Rica. FN(:I 1987:79:1247-5t.

5 Paul C, Skegg DCG, Smeiiers J. Spears GFS. Contraceptive practice in New Zealand. W\%. Hed 7 1988;101:809-13.

6 Paul C, Skegg DC, (i, Spears GFS, Kaldor JM. Oral contraceptives and breast cancer: a national studv. Br.Med F 1986;293:723-6.

7 Skegg DCG. Potential for bias in case-control studies of oral contraceptives and breast cancer. Am 7 Epidemiol 1988:127:205-12.

8 Miller AB, Bulbrook RD. UICC multidisciplinary project on breast cancer: the epidemiology, aetiology and prevention of breast cancer. Int 7 Cancer $1986 ; 37: 173-7$

9 Bruzzi P, Negri E, La Vecchia C, et al. Short term increase in breast cancer risk following a full term pregnancy. Br. Hed f.1988;297:1096-8.

10 Hall PE. Long-acting injectable formulations. In: Diczfalusv E, Bvgdeman $\mathrm{M}$, eds. Fertility regulation today and tomorrow. New York: Raven Press. 1987:119-41. (Serono symposia publications, vol 36 .

11 Korenman SG. Oestrogen window hypothesis of the aetiology of breast cancer. Lancet 1980;i:700-1.

12 Henderson BE, Ross RK, Judd HL, Krailo MD, Pike MC. Do regular ovulatory cycles increase breast cancer risk? Cancer 1985;56:1206-8.

Pike MC. Ross RK. Breast oncer. Br Med Bull 1984:40:351-4.

14 Briggs $M$. The beagle dog and contraceptive steroids. Life Sci 1977;21:275-84

15 Fraser IS, Weisherg E. A comprehensive review of injectable contraception Fraser IS, Weisherg E. A comprehensive review of injectable contraception
with special emphasis on depot medroxyprogesterone acetate. Hid $\mathcal{f}$. Aust

16 Greenspan AR, Hatcher RA, Moore M, Rosenberg MJ, Ory HW. The association of depo-medroxyprogesterone acetate and breast cancer. (omtraception 1980;21:563-9.

17 Liang AP, Levenson AG, Layde PM, et al. Risk of breast, uterine corpus, and ovarian cancer in women receiving medroxyprogesterone injections. $7 \mathrm{AMA}$ $1983 ; 249: 2909-12$.

Accepled 3 fuly 1989

David E Neal, Peter D Ramsden, Linda Sharples, Andrew Smith, Phillip H Powell, Rosemary A Styles, Ralph J Webb

Abstract

Objectives-To determine the symptomatic and to establish whether the outcome is influenced or can be predicted by preoperative urodynamic measurements.

Design-Prospective non-randomised study with follow up at a mean of 11 months after operation.

Department of Urology, Freeman Hospital, Newcastle upon Tyne NE7 7DN

David E Neal, FRCS, senior lecturer in urological surgery Peter D Ramsden, FRCS, consultant urologist Phillip H Powell, FRCS, consultant urologist Rosemary A Styles, FRCS, senior urological registrar Ralph J Webb, FRCS, urological research fellow

Medical Research Council Biostatistics Unit, Cambridge

Linda Sharples, PHD, lecturer in statistics

Whickham, Tyne and Wear Andrew Smith, FRCGP, general practitioner

Correspondence to: Mr Neal.

BrMed F 1989;299:762-7

Intervention-Elective prostatectomy.

Main outcome measure-Classification on the basis of relief of symptoms assessed by patients and urologist and general practitioner and of symptom scores obtained by questionnaire.

Results - Of the 217 men followed up, $171(79 \%)$ had a satisfactory subjective review and $155(72 \%)$ had a satisfactory review and also low symptom scores. An unsatisfactory outcome was associated with preoperative symptoms of urge incontinence, small prostatic size and resected weight, low voiding pressures, and low urethral resistance. Preoperative maximum urinary flow rates did not predict outcome. Men with poor outcome could be classified into two groups: those with irritative symptoms who were more likely before operation to have had urge urodynamic outcome of elective prostatectomy and

incontinence and detrusor instability and men with symptoms of poor urinary flow who were more likely before operation to have had a small prostate, low voiding pressures, and low urethral resistance. In patients in the second group flow rates or voiding pressures improved little after operation. Men with stable detrusors and either low urethral resistance or low voiding pressures were less likely to do well after prostatectomy, but despite these associations preoperative urodynamic measurements were unable to predict outcome accurately.

Conclusions-Prostatectomy was satisfactory in relieving symptoms and improving urodynamic measurements in most men, but even in those with classic symptoms and low urinary flow rates a substantial minority experienced little improvement afterwards and urodynamic measurements did not accurately predict outcome in individual patients. brovascular disease; $217(86 \%)$ were followed up

\section{Introduction}

Men in their 40s contemplating the one in 10 chance of future prostatectomy ${ }^{2}$ will be reassured that the operation is safe ${ }^{3}$ but may be disquieted by recent reports, which found that a fifth of men required a second transurethral operation within eight years, ${ }^{+}$that many experienced little improvement in quality of life assessment, ${ }^{5}$ and that persistent urinary problems were commonplace. ${ }^{6}$

In about a fifth of men prostatectomy is performed for acute or chronic retention of urine,, 7 but in the remainder it is carried out for symptoms of bladder outflow obstruction that are difficult to assess. Moreover, similar symptoms may be produced by an un- 